\title{
Minimization of heat gains in buildings: The case of domestic buildings in Cape Coast Metropolis - Ghana
}

\author{
Samuel Kwame Ansah*
}

Department of Building Technology, Cape Coast Polytechnic, P.O Box AD 50, Cape Coast, Ghana

\begin{abstract}
This research aims at ascertaining appropriate construction designs and techniques that could be adopted to minimize excessive heat gains in buildings. Random sampling technique was used for selecting hundred (100) domestic buildings in each of the three densely populated suburbs considered within the Cape Coast Metropolis in Ghana. In total, three hundred (300) buildings were used as a sample for this study. Structured interview and observation were used as the main research methods to obtain the necessary data for the study objectives. The results show that appropriate construction designed methods and techniques were not adopted for the construction of almost all the buildings investigated. It was also realized that majority of the occupants (96\%) used electric fans, and air conditioners to reduce the amount of heat gains in their rooms. The study suggested that, shading techniques such as screens to walls, fixed sun breakers and attached canopies must be encouraged in the design and construction of buildings. The study also suggested that all buildings, yet to be constructed, should be positioned with their longest walls facings north and south in order to reduce intense morning and evening sun entering into the building with more window openings accommodated in both sides of the longest walls to allow for crossventilation.
\end{abstract}

Keywords: Appropriate design, Heat gains, Heat minimization, Techniques

Copyright (C) 2012 by the Author(S) - Published by ISDS LLC, Japan

International Society for Development and Sustainability (ISDS)

Cite this paper as: Ansah, S.K. (2012), "Minimization of heat gains in buildings: The case of domestic buildings in Cape Coast Metropolis - Ghana", International Journal of Development and Sustainability, Vol. 1 No. 3, pp. 994-1007.

\footnotetext{
*Corresponding author. E-mail address: skansah@hotmail.co.uk
} 


\section{Introduction}

Excessive heat gains in tropical buildings which call for the use of expensive artificially generated electrical energy need to be minimized by the use of more cost effective and equally durable construction materials and techniques (Burberry, 1993). It is a common knowledge that heat discomforts have been a major source of worry to many, especially occupants of dwelling houses and public buildings in hot climatic conditions. Progress, though, has been made in finding solution to heat gains into building within the tropics by positioning buildings to allow natural ventilation, by the use of some materials of high resistance to heat transfers and by the use of artificial air conditioners or fans which may require electricity and other forms of man-made energy to operate them.

In cold climatic or temperate regions heat gains into buildings or into rooms is more advantageous and desirable, but the vice versa in the tropics (Jones, 2001). In excessive hot climates, it is necessary to reduce temperature and humidity, whiles in excessive cold climates it becomes necessary to increase them. Therefore, there is a definite range of temperature and humidity, within which efficiency and comfort can obtain (Burberry, 1993). Human beings can only work and live with comfort and efficiency within a registered set of physical conditions and when these conditions cannot be provided, health suffers and in extreme cases epidemics occur resulting in deaths (Faber, 1996). It should be noted that one major contributing factor to human health problem is ambient temperature. It is therefore the duty of the designer (or the air condition engineer, where applied) to produce efficiency and comfort conditions, in collaboration with the architect, at the lowest cost having regard to cleanliness, convenience and appearance. Since the emergence of modern architecture in especially the developing countries, much emphasis has been placed on strength and durability of conventional materials and the stability of structures more, with rather a lesser attention on construction techniques to enhance heat reduction in the design of structures (Allard, 1998). According to Ampadu-Asiamah and Adjei (2011), many writers over the years have agreed to the fact that buildings irrespective of their locations/positions, supposed to provide comfort, be functional, and environmentally friendly or sustainable.

Unfortunately today, designs are inappropriate and artificial energy is widely used for creating comfort in rooms. Construction rethinking and design options which could counteract heat gains in domestic and institutional buildings therefore needs to be considered in order to reduce the prevailing discomfort temperature in buildings. This research is therefore conducted to find out the most suitable and appropriate construction designs, techniques and materials that can significantly be used for the construction of domestic buildings in tropic regions in order to reduce or counteract excessive heat gains into such buildings. The specific objectives of the study are:

- To find out the temperature level in each of the buildings under study.

- To find out whether occupants living in various buildings are satisfy with their indoor conditions without the use of artificial ventilation.

- To find out the type of ventilation systems used by the occupants to achieve ventilation in their rooms. 


\section{Literature review}

\subsection{The need for thermal comfort}

Thermal comfort of human beings is governed by many physiological mechanisms of the body and these vary from person to person. As intimated by Osbourn (1993), thermal comfort is the environmental conducive hot or cold condition suitable for human habitation and efficiency. Depending upon the climatic conditions of the locality, a satisfactory thermal environment is an important purpose of good building design. A satisfactory and conducive thermal environment is an important condition for normal and healthy functioning of human system, as it allows the internally generated body heat to dissipate by convection to obtain the normal body temperature for continuous functioning.

Continuous stay in high temperatures, apart from the unpleasant discomfort and loss of tone created, would cause very serious health hazards (Allard, 1998). Uncomfortable heat in rooms causes very high rate of blood circulation, causing excessive sweating which results in fluid and salt loss from the body. It also causes inflammatory skin reactions and heat rashes. The condition is very much associated with heat exhaustion, respiratory infections in minor cases. In extreme cases excessive heat could result in heat stroke, sudden collapse and loss of consciousness (Ghana Health Service - Public Health Division, Cape Coast).

\subsection{Requirement of buildings built in warm humid climates}

The requirements of buildings built in warm humid climate region has been discussed by many writers over the years and they all agreed to the fact that buildings in this region like all other buildings elsewhere supposed to provide comfort, be functional, and environmentally friendly or sustainable (Ampadu-Asiamah and Adjei, 2011). According to Koenisberger et al., (1980), buildings have to be opened up to breezes and oriented to catch available air movement in order for heat to be removed from the occupants' body into the environment. Other features that were suggested by Koenisberger et al. (1980) are shading devices to reduce radiation from the sky.

According to Lloyd (1998), some of the important considerations for building in tropical regions are 'natural ventilation, mechanical ventilation, artificial cooling, free cooling, light weight construction, day lighting and solar shading/control'.

Another writer, Stagno (2001) also suggests that in order to achieve an acceptable level of comfort in buildings in the tropics, consideration must be given to variables like 'air-cooling, decreasing relative humidity levels and reduction of excessive glare from the sun' and existing environmental factors.

According to Bay and Ong (2006), 'shading devices with verandas, sun breaks and appropriate openings are always more efficient and cheaper for climatic control in subtropical regions'.

Below are some sustainability requirements relating to the design and construction of building envelope:

- It is essential to consider the local climatic conditions (temperature, moisture, wind) in order to know the materials for construction of the buildings envelope and the overall energy performance of the building (Bolin, 2009). 
- Design to make maximum use of natural light whiles being aware of its limitations (Bolin, 2009), (Smith, 2006).

- Using Effective Solar Shading Devices especially exterior shading devices such as overhangs, vertical fins and light shelves as energy efficiently measures (Bolin, 2009).

- Providing windows that afford building occupants views outside but do not negatively impact the visual and acoustic comfort of the work environment (Bolin 2009).

- Components of the buildings envelope should adequately address issues of thermal comfort at the building perimeter, particularly thermal and solar performance (Bolin, 2009), (Smith, 2006).

- The potential for natural ventilation in the context of an overall climate control strategy must be exploited while minimizing energy use and maximizing comfort. Where appropriate, the use of operable windows for natural ventilation and occupant control must be considered (Bolin, 2009), (Smith, 2006).

\subsection{Climate responsive buildings}

According to Gut and Ackerknech (1993), climate responsive building involves the application of soft measures and natural means to reduce energy consumption by design, construction and materials appropriate for a specific climate. It is a very comprehensive approach, dealing particularly with buildings in tropical climate zones (Gut and Ackerknech, 1993). Gut and Ackerknech (1993) further stated that, the main points to be taken into consideration when designing a climate responsive building are:

- Minimization of heat gain during daytime and maximize heat loss at night in hot seasons, and reverse in cold seasons

- Minimization of internal heat gain in the hot seasons

- Selection of the site according to microclimate criteria

- Controlling of solar radiation

- Regulating of air circulation

\subsection{Passive climate control}

The concept of passive climate control is completely in line with the notion of sustainable building. It concentrates on building physics and ensures that the temperature and the relative humidity stay within acceptable ranges. According to Burberry (1993), the creation of thermal comfort within a building by passive means, involves the use of building elements themselves to reduce heat gains from the outside to the inside in warmer climates. In this case the transfer of heat is regulated by the external fabric (external walls and roofs) of a building and its prevention depend upon thickness of the building elements, system of construction, climate of locality and the degree of exposure (Burberry, 1993). High efficiency windows and insulation to walls, ceiling, and floors may be used to increase the efficiency of the building envelop (Johnston and Gibson, 2008). International comparisons show that builders generally use structures having a small 
surface area with heavily insulated building elements (walls, floors and roofs) to achieve a stable internal environment (Christofferson, 1995).

\subsection{Description of study area}

Amanful-Idan, Gyegyem-Enyitsiwdo and Abura are three very large densely populated suburbs in the heart of Cape Coast Metropolis in Ghana. A pre-study of these communities revealed that a majority of buildings in these communities were put up even before the passage of the Town and Country Planning Act (Ghana 1994). Even after the passage of the Town and Country Planning Act in 1994, the lands in these communities could not be demarcated for proper planning because of the way and manner buildings have already been scattered and crammed together on these lands. People living in these communities, because of their closed family relationships, preferred to put up their buildings closed to each other in order to increase or maintain their family relationship. It was also noted that majority of building owners in these communities put up their buildings without seeking for building permit or approval from the Cape Coast Metropolitan Assembly Authorities and this has therefore resulted in poor buildings siting in these communities.

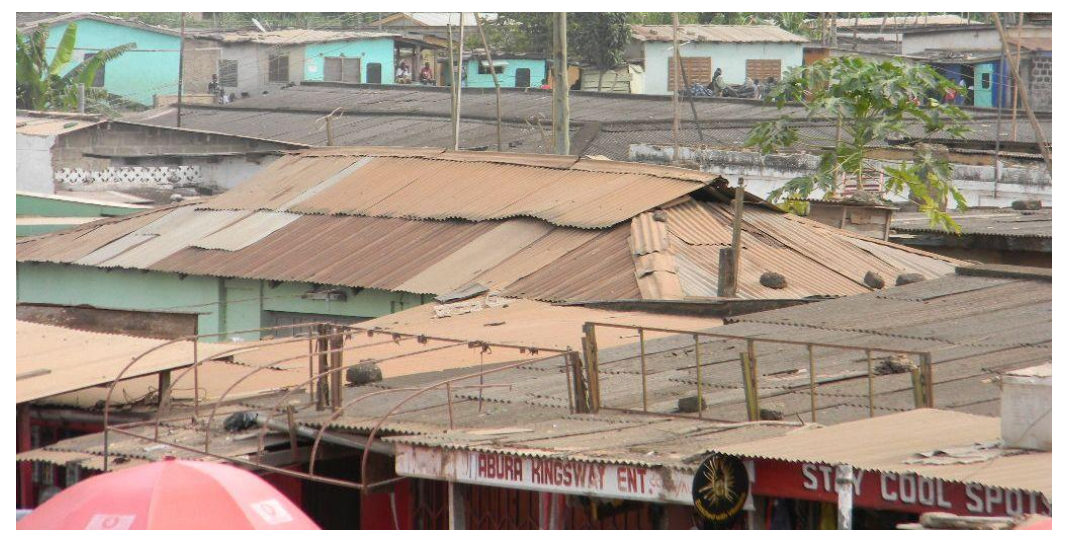

Plate 1. Showing Part of Settlement of Abura Community

There are all classes of people and buildings settlement in these communities. Majority of the residential settlers in these communities are average to low class people with most of their buildings in relation to land and the environment, not properly designed and not well laid out. These communities could be graded as the slum area of township because of these communities been over populated; having less developed housing system and ill-planned layout. Gilbert (2007) informs that 'slum' is nowadays employed to describe 'bad' shelter. The word slum is used at a varying scale in that a house or a large settlement can be tagged slum provided it is perceived to be substandard and is occupied by the poor. Gilbert (2007) further informs that "every urban area in the world tend to define slums differently, even though efforts have been made for years to establish objective measures with which to demarcate the major problem areas". Furthermore, the UN-HABITAT report (2003) on "the challenge of slums", defines "slum" as "household or group of 
individuals living under the same roof that lack one or more of the following conditions: access to pipe borne water; access to sanitation; secure tenure; durability of housing; and sufficient living area". This working definition, officially adopted at a UN meeting in Nairobi on October 2002, is "restricted to the physical and legal characteristics of settlement," and according to Kim (2008) this definition shies away from the more difficult-to-measure social dimensions associated with slum. However, in most cases it is equally related to both the economic and social circumstances of individual or community (UN-Habitat, 2003).

\section{Research methods}

The study was based on the data collected from three communities within Cape Coast Metropolis in Ghana. The study utilized both secondary and primary sources of data. Primary information was collected from both direct interviews and personal observations. Researchers retrieved information from internet, text books, conference papers and journals and used it as a secondary data for the study. The interviews were conducted in a semi-structured format that allows respondents to express their own view points (Flick, 2002). The semi-structured face-to-face interview was designed to qualitatively analyze respondents free format comments on the main subject. To solicit information on temperature level in each room, no structured questionnaire was designed for the respondents since majority of them would not be in the position to know the exact temperature levels in the building/rooms they occupy. With deep explanation and persuasion, all the respondents allowed researchers access to their rooms for the room temperatures to be recorded. The researchers used room thermometers to read the actual room temperatures of the selected room in the study area. The room temperatures were recorded in four sunny days in the month of October and November, 2011 between the hours of 12 noon and $4 \mathrm{pm}$.

In each of the three selected suburbs, one hundred (100) domestic buildings were randomly selected for the study. In total, three hundred (300) buildings were selected for the study. Two (2) adults or leading members living in each of the sample buildings were contacted for the interview. In all, six hundred (600) persons living in the sample buildings were interviewed to know how they feel especially in the peak of sunny periods regarding interior comfort/heat discomfort and how they overcome such problems.

Personal observations were also made by the researchers to enable them assess the degree of the problem in each case, noting the design of the buildings, the type of buildings, position of the buildings in relation to wind flow/direction and degree of exposure of buildings to the sun or day light.

Table 1. Name of Communities, Number of Buildings Investigated and Number of Respondents

\begin{tabular}{lcc}
\hline Community Name & Number of buildings investigated & Number of persons interviewed \\
\hline Amanful-Idan & 100 & 200 \\
Gyegyem-Enyitsiwdo & 100 & 200 \\
Abura & 100 & 200 \\
Total & $\mathbf{3 0 0}$ & $\mathbf{6 0 0}$ \\
Percentage & $100 \%$ & $100 \%$ \\
\hline
\end{tabular}


Table 2. Room Temperature taken

\begin{tabular}{ccc}
\hline Approximate recorded Room Temperature & Number of rooms (Frequency) & Percentages (\%) \\
\hline $\mathbf{3 6}^{\circ} \mathbf{C}$ & 68 & 22.67 \\
$\mathbf{3 5}^{\circ} \mathbf{C}$ & 121 & 44.33 \\
$\mathbf{3 4}^{\circ} \mathbf{C}$ & 47 & 15.67 \\
$\mathbf{3 3}^{\circ} \mathbf{C}$ & 45 & 15.00 \\
$\mathbf{3 2}^{\circ} \mathbf{C}$ & 19 & 6.33 \\
Total & $\mathbf{3 0 0}$ & $\mathbf{1 0 0 \%}$ \\
\hline
\end{tabular}

Table 3. Structured interviewed response from occupants living in domestic buildings

\begin{tabular}{lccc}
\hline & Yes (\%) & No (\%) & Partially (\%) \\
\hline $\begin{array}{l}\text { Staying (living) in the domestic room } \\
\text { with artificial ventilation? }\end{array}$ & 93 & 4 & 3 \\
$\begin{array}{l}\text { Satisfaction with indoor condition of } \\
\text { the domestic room without artificial } \\
\text { ventilation. }\end{array}$ & 0 & 97 & 3 \\
$\begin{array}{l}\text { Using air conditioner in the room } \\
\text { Using fan in the room }\end{array}$ & 2 & 92 & 6 \\
\hline
\end{tabular}

Table 4. Types of building fabric/facade identified in the research area.

\begin{tabular}{|c|c|c|}
\hline Type of building fabric & Number of Building & Percentage (\%) \\
\hline Clay bricks/Adobe walls & 91 & 30.33 \\
\hline Sandcreate blocks walls & 162 & 54.00 \\
\hline Concrete walls & 0 & 0.00 \\
\hline $\begin{array}{l}\text { Timber framed and cladded } \\
\text { walls }\end{array}$ & 5 & 1.67 \\
\hline Metal sheet & 0 & 0.00 \\
\hline Glass walls & 0 & 0.00 \\
\hline $\begin{array}{l}\text { Combination of materials } \\
\text { (composite) walls }\end{array}$ & 15 & 5 \\
\hline Stone walls & 0 & 0.00 \\
\hline $\begin{array}{l}\text { Mud buildings/Atakpame } \\
\text { walls }\end{array}$ & 27 & 9.00 \\
\hline Total & 300 & $100 \%$ \\
\hline
\end{tabular}




\section{Survey analysis and discussion}

Out of the total number of 300 buildings investigated, 68 of the buildings representing $22.67 \%$ of the total number of buildings recorded the highest temperature of $36^{\circ} \mathrm{C} ; 121$ of the buildings representing $40.33 \%$ of the total number of buildings recorded $35^{\circ} \mathrm{C} ; 47$ of the buildings representing $15.67 \%$ of the total number of buildings recorded $34^{\circ} \mathrm{C} ; 45$ of the buildings representing $15 \%$ of the total number of buildings recorded $33^{\circ} \mathrm{C}$; and 19 of the buildings representing $6.33 \%$ of the total number buildings recorded the lowest temperature of $32^{\circ} \mathrm{C}$. Average recorded room temperature for all the 300 buildings investigated was $33.6^{\circ} \mathrm{C}$. The highest frequency of temperature recorded in the case study area is $36^{\circ} \mathrm{c}$. This alluding to the fact that heat gain is very much present in poorly designed and constructed buildings within the metropolis and that warrants the over-reliance on mechanical means of creating comfort conditions in rooms. It was realized that out of 600 persons interviewed, 558 persons representing 93\% fully rely on the use of artificial ventilation systems. Again18 persons representing 3\% of the persons interviewed partially depend upon the use of artificial ventilation systems. Only 24 (4\%) of the persons interviewed do not depend on artificial ventilation.

\subsection{Wall and roof system}

Block walls have the tendency to absorb solar heat and transmit them especially during the later part of the day, thus creating uncomfortable room conditions if not well ventilated. Out of the survey of 300 buildings, 162 of the buildings representing 54\% were built using sandcrete blocks.

There were quite a number of clay brick houses found in the case study communities. Out of the 300 buildings under study, 91 of the buildings representing 30.33\% were constructed from clay bricks (Adobi). In relation to its thickness, clay brick walls possess the quality of slowly absorbing solar heat, thus, reducing the rate of heat transfer through it.

There were a few timber buildings observed in the case-study area. It was found that 5 of the buildings representing $1.67 \%$ of the 300 buildings surveyed were completely constructed from timber. Wood itself is a natural heat insulator because of its cellular structure. It has a great resistance to heat than steel and aluminium, though combustible. Having a low thermal conductivity, timber has been placed among the range of moderately good heat insulating materials. Is must be emphasized that if the full value of its insulating properties is to be maintained, there must be no air gaps between individual boards, that is, close joints must be used, or the timber cladding must be lined with drought proof materials.

Out of the survey of 300 buildings, 15 of the buildings representing $5 \%$ were found to be constructed from combination of building materials (composite materials). Also, 27 buildings representing 9\% of the 300 buildings under study were found to be constructed from mud clay (compressed earth) commonly known in Ghana as 'Atakpame'.

Observations revealed that single storey buildings with flat or monopitch roofs having no suspended ceiling were characterized by various levels of very uncomfortable heat in the rooms. Buildings with couple and other types of pitched roof, depending upon the degree of pitch exhibited similar conditions of heat discomfort. 
In a typical stable sunny condition the concrete roof and wall was observed to accumulate the solar heat during the first half of the day (i.e. after sunrise) and begins emitting the accumulated heat during the midafternoon or soon after mid-day, and the discomfort experienced could continue into the night. Similar condition was experienced in buildings with asbestos but has far less conductivity than concrete, the thickness of the roof covering permits faster transfer or transmission rate.

Cement-sandcrete and concrete buildings having concrete roofs and with no suspended ceiling exhibited the highest level of heat emission into rooms, alluding to the fact that dense in-situ concrete has a very high level of thermal conductivity $\left(1.43 \mathrm{w} / \mathrm{m}^{\circ} \mathrm{C}\right)$, among the common building materials.

\subsection{Building orientation}

Heat gains and emission take various dimensions owing to diverse layouts and orientation of buildings. The presence of heat in buildings within the study area has a high connection with orientation in relation to the sun path. Where the position of the building permits direct sun rays into rooms through doors and window gives cause for multi-reflection of heat in the rooms. Where the wider area of a building is oriented in line with the sun or solar path, maximum heating of the building must be expected in both morning and afternoon, unless the same orientation permits natural ventilation thereby reducing the heat build-up in walls naturally.

\subsection{Location of the Buildings and Degree of Exposure}

Location of buildings is determined by a number of factors, some of which are the type of building or structure, the use of the building, the availability of land, the choice or taste of the client, demographical and sociological concerns of the locality, and the Local/District Authority regulations among others. Whatever the deciding factor, the location of the building should serve the purpose with regards to efficiency and comfort. Heat discomfort would occur in buildings over-shadowed by adjacent tall buildings or hill, to the extent of breaking the wind flow from ventilating the concerned building.

Owing to the scarcity of land, a great number of residential buildings in the case study area are sited at where relief winds over-pass the buildings thereby depriving them of adequate ventilation. It was observed that wider spacing of buildings enhances free flow of air but the situation of greater surface area of a building exposed to solar radiation with no 'green' environment and other sun shades, subjects the building to heat build-up.

It was found that thermal discomfort is quite intensive in buildings overshadowed by adjacent hills or tall buildings preventing easy air flow and therefore causing some level of air stagnation in the rooms most of the day. Heat in such situations, even where emitted at the roof, can be felt at the floor level by radiation. Buildings with two or more storeys have their lower floor rooms experiencing somehow lesser heat transmission. This depends on the degree of exposure to sun rays, and even when they are not very comfortable, they are deemed manageable, with the exception of those encountering direct solar heat radiation owing to east-west positioning of the building. It is also observed that upper floor rooms and 
building fabric provide a kind of shading to the lower floor rooms thus reducing the amount of wall and roof area exposed to solar heat, thereby reducing the amount of heat transmission into rooms.

Well designed and finished residential buildings especially those painted in white and other light colours are found to absorb less heat as compared to those finished in darker and heavier colours.

Plates 2 to 9 below show some of the sample buildings in the selected communities.

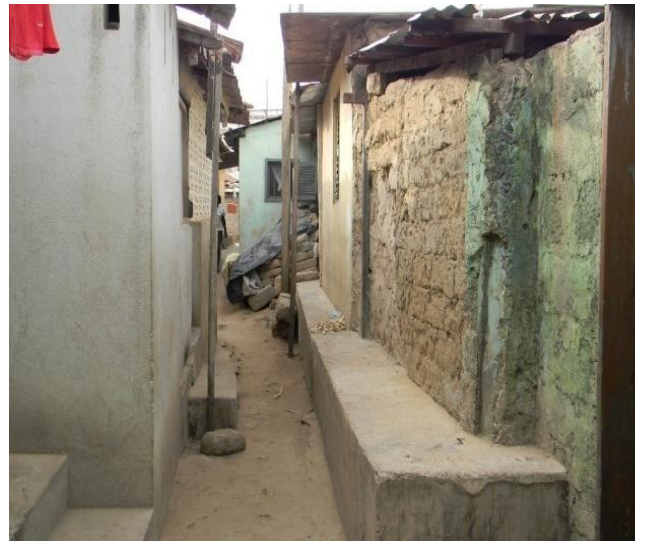

Plate 2. Located at Gyegyem-Enyitsiwdo

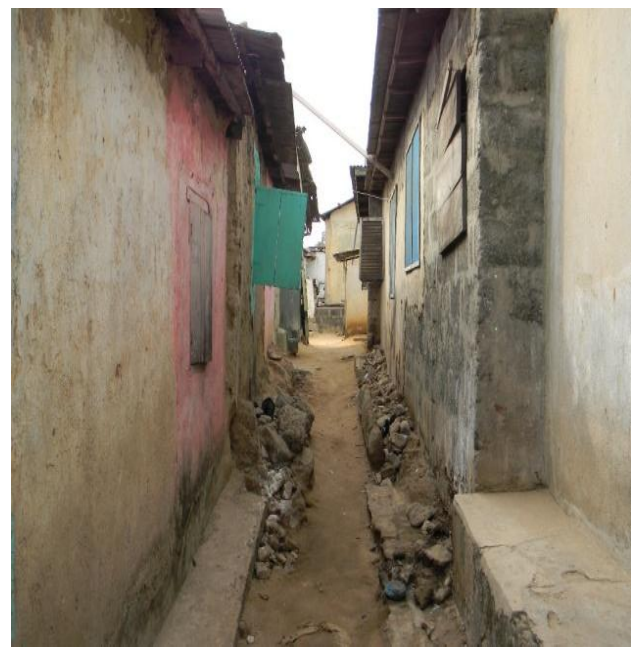

Plate 4. Located at Gyegyem-Enyitsiwdo

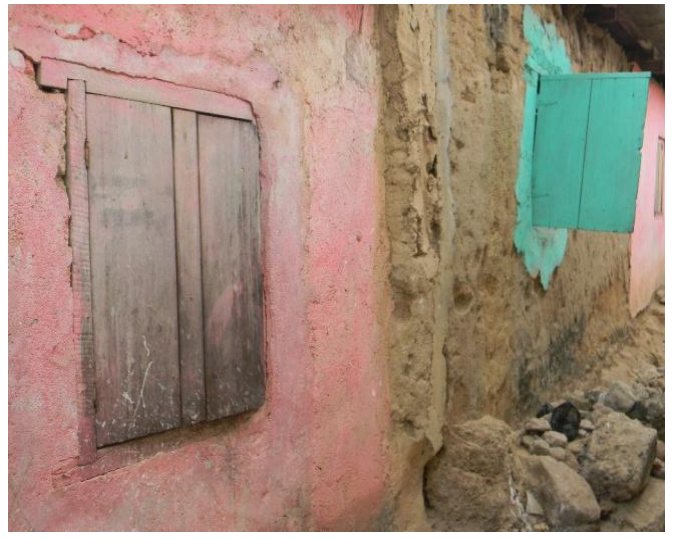

Plate 3. Located at Gyegyem-Enyitsiwdo

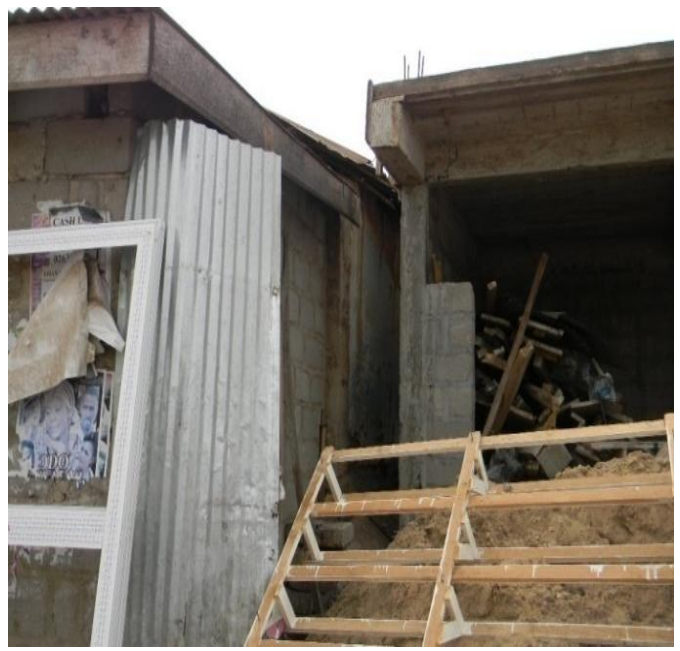

Plate 5. Located at Amanful-Idan 


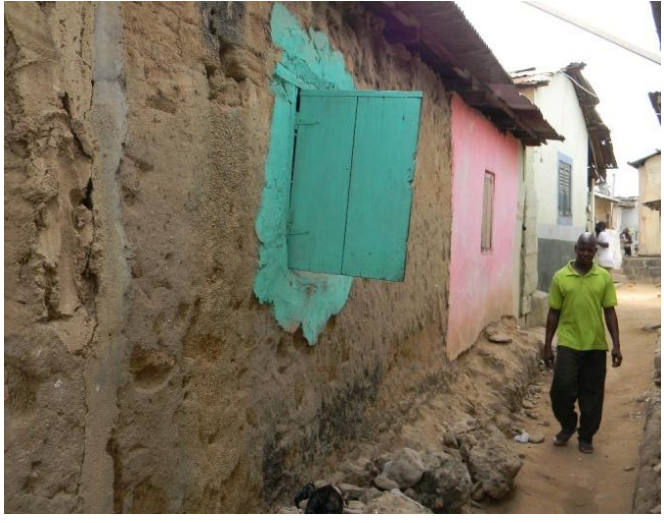

Plate 6: Located at Gyegyem-Enyitsiwdo

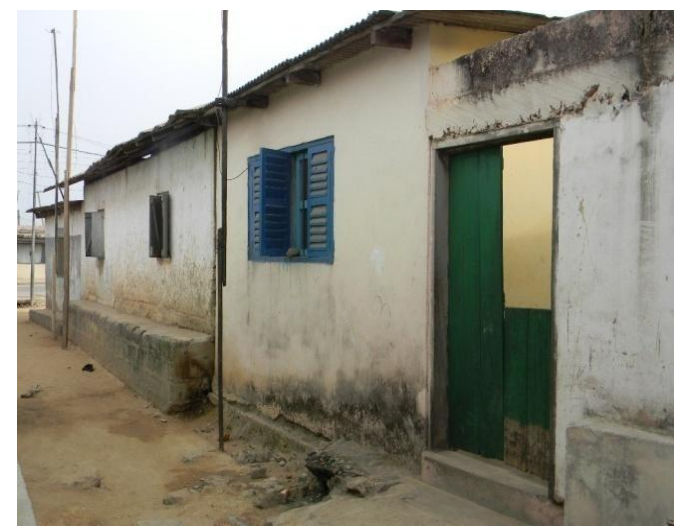

Plate 8. Located at Amanful-Idan

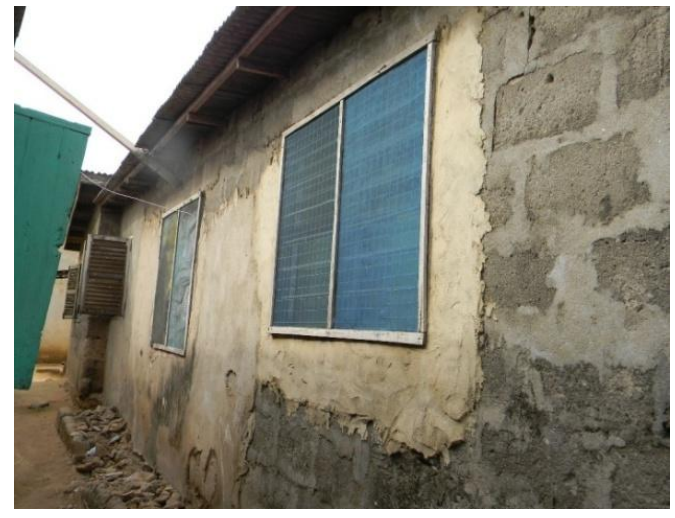

Plate 7: Located at Gyegyem-Enyitsiwdo

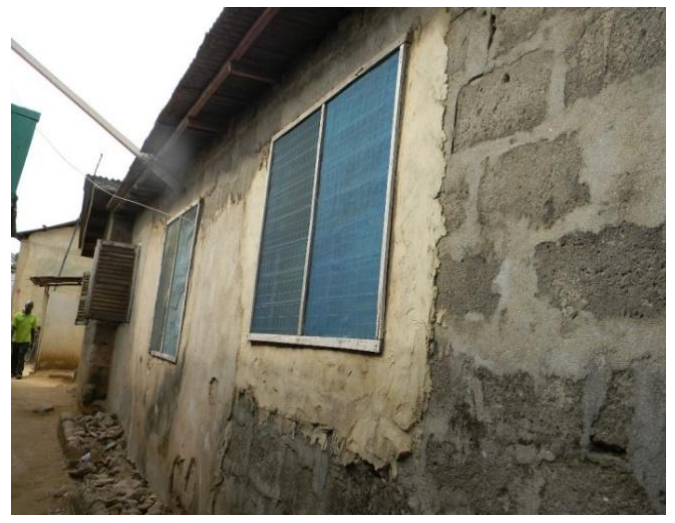

Plate 9. Located at Gyegyem-Enyitsiwdo

\section{Conclusion}

Buildings are built to protect their inhabitants against the extreme outdoor conditions and create comfortable indoor conditions. It must be noted that the requirements for buildings built in warm humid climate region like all other buildings elsewhere supposed to provide comfort, be functional and environmentally friendly or sustainable. The study revealed that a majority of the buildings built in the case study area were not climate responsive buildings.

The results showed that appropriate construction design methods and techniques were not adopted for the construction of almost all the buildings investigated. This has resulted in excessive heat gains in the buildings, which leads to rooms discomfort and to reduce this, it has called for the use of fans and air conditioners which rely on expensive artificially-generated electrical energy to operate them. It was realized 
that a majority of the occupants (96\%) used electric fans, and air conditioners to reduce the amount of heat gains into their rooms.

The study suggested that, shading techniques such as screens to walls, fixed sun breakers and attached canopies must be encouraged in the design and construction of buildings. The study also suggested that all buildings, yet to be constructed, should be positioned with their longest walls facing north and south in order to reduce intense morning and evening sun entering the building with more window openings accommodated in both sides of the longest walls to allow for cross ventilation.

\section{Recommendations}

The following recommendations and suggested techniques are presented as measures to overcome excessive heat gains in buildings:

\subsection{Finishing to existing structure elements}

i. All finished concrete roofs having persistent heat problem should be refinished with screed and reflective chippings overlay, reflective felt or white polished ceramic tiles overlay. Alternatively, the concrete roof should be re-designed to incorporate solar slabs or hollow concrete blocks of about $150 \mathrm{~mm}$ thick with $32 \mathrm{~mm}$ water proof screed overlay, to form insulation in the roof.

ii. A well designed concrete roof can also be sheltered against heat by providing a thick high class damp proof sheet membrane, and topped with at least $150 \mathrm{~mm}$ compost soil and carpet grass for overhead/roof greenery.

iii. All unfinished or improperly finished buildings which have their end walls against direct solar radiation (East-West) can have their external surfaces finished with an attached non-load bearing hollow block or clay brick wall, or the external wall finished with $15 \mathrm{~mm}-18 \mathrm{~mm}$ render of rough-cast finish with reflective chippings surface.

\subsection{Ceiling}

All non-ceiled asbestos and zinc or galvanized roof coverings (and concrete roofs where possible) should be ceiled in rooms and at the eaves and verges. It is recommended that expanded polystyrene sheets, fibre board (soft board) or coconut fibre mats which are all common in Ghana, be incorporated in ceilings as insulation against heat.

\subsection{Ventilation}

iv. As much as possible, adequate natural ventilation of rooms and the building as a whole must be allowed for by providing wider door and window openings. 
v. For buildings already in place alterations can be done to create induced ventilation, and for on-going and yet to be constructed buildings in clustered areas, Wind Tower and Stack effect ventilation techniques can be applied.

vi. Fanlights over doors and windows, and ventilation ducts in ceiled roofs should be utilized as much as possible to enhance air flow in buildings and thus prevent heat build-ups in rooms.

\subsection{Orientation of building}

For all buildings yet to be constructed in the Metropolis, it is desirable that they are oriented with their longest walls facing north and south with more window openings incorporated opposite to each other in this longest walls to allow for cross-ventilation. The short walls should always built to face east and west so that only the smallest wall areas are exposed to intense morning and evening sun.

\subsection{Shading}

Shading by trees and vegetation is a very effective method of cooling the ambient hot air and protecting the building from solar radiation. This and other shading techniques such as by extended roof overhangs, louvers, textured façade, screens to walls, attached canopies and fixed sun breaker must be encouraged by the projects section of the Metropolitan assembly.

\section{References}

Allard, F. (1998), Natural Ventilation in buildings: A design handbook, $3^{\text {rd }}$ ed., James and James, London.

Ampadu-Asiamah, A.D. and Adjei, E.A. (2011), "Factors influencing the extensive use of glass on facades of office buildings in Accra", in Laryea, S., Leiringer, R. and Hughes, W. (Eds), proceedings of West Africa Built Environment Research (WABER) Conference, 19-21 July 2011, Accra, Ghana, 473 - 485.

Bay, J.H. and Ong, B.L. (2006), Tropical sustainable architecture: Social and Environmental dimensions, Architectural Press, Oxford.

Bolin, R. (2009), "Sustainability of the Building Envelope", National Institute of Building Sciences, available at: www.wbdg.org/design/envelope (accessed 6 March 2011).

Burberry, P. (1993), Practical thermal design in buildings, 2 ${ }^{\text {nd }}$ Ed., Batsford Academic and Educational, London. Christoffersen, L.D. (1995), Zephyr: Passive climate controlled repositories: Storage facilities for museum, archive and library purposes, Department of Building Physics, Lund University, Sweden.

Faber, O. (1996), Heat and Ventilation, E. \& F. N. Spon Ltd, London.

Flick, R. (2002), An Introduction to Quantitative Research, Sage Publications Ltd, London.

Gilbert, A. (2007),"The return of the Slum: Does Language Matter?”,International Journal of urban and Regional Research, Vol. 31 No. 4, pp.697-713. 
Gut, P. and Ackerknecht, D. (1993), Climate Responsive Building: Appropriate Building Construction in Tropical and Subtropical Regions, SKAT, Swiss Centre for Development Cooperation in Technology and Management, St. Gallen, Switzerland.

Johnston, D. and Gibson, S. (2008), Building Green, Home Publishers Press, U.S.A.

Jones, W.P. (2001), Air Conditioning Engineering, 5th ed., Butterworth-Heinemann Publishers, Oxford, Great Britain.

Kim, L. (2008), The Kijiji kit: A strategy for slum upgrading in Nairobi, University of Water loo, Ontario, Canada. Koenisberger, O.H., Ingersoll, T.G., Mayhew, A. andSzokolay, S.V. (1980), Manual of Tropical Housing and Building, Longman Group limited, London.

Lloyd, J.D. (1998), Architecture and the Environment-Bioclimatic Building Design, Laurence King Publishing, London.

Osbourn, D.C. (1993), Introduction to Building, Longman Singapore Pte Ltd, Singapore.

Smith, P.F. (2006), Architecture in a climate of Change - A guide to sustainable Design, 2nded., Architecture Press, Oxford.

Stagno, B. (2001), "Designing and building in the tropics", available at: www.brunostagno.info (accessed 4 April 2011).

United Nations Human Settlements Programme (UN-HABITAT), (2003), The Challenge of slums: Global Report on Human Settlements, Earthscan, London, UK. 